\title{
The Asymmetrical Architecture of New Optical Switch Device
}

\author{
Mohammad Syuhaimi Ab-Rahman and Boonchuan Ng \\ Universiti Kebangsaan Malaysia (UKM) \\ Malaysia
}

\section{Introduction}

The explosive growth of data and combusting traffic have led to a demanding of flexible, efficient, survivable, and multifunctional device to support all of network functions, management and testing. The sophisticated technologies today had led to realize any complex design in optical architecture that has become impossible for some years ago. The waveguide technologies become the first player in developing the new architecture of optical switch device. The most optical devices today are built by symmetrical architecture. Therefore, they can perform bi-directionally with the same function to both side of incoming signal.

The introducing of new optical switching device named optical cross add and drop multiplexing (OXADM) which has an asymmetrical architecture and can perform bidirectionally function as the previous using the combination concept of optical cross connect $(\mathrm{OXC})$ and optical add and drop multiplexing (OADM). Its enable the operating wavelength on two different optical trunks to be switched to each other while implementing add and drop function simultaneously. With the asymmetrical architecture, its enable the operating wavelength on two different optical trunks to be switched to each other and implementing accumulating function simultaneously. Here, the operating wavelengths can be reused again as a carrier of new data stream. The wavelength transfer between two different cores of fiber will increase the flexibility, survivability, and also efficiency of the network structure. To make device operational more efficient, micro-electromechanical system (MEMS) switches are used to control the mechanism of operation such as wavelength add/drop and wavelength routing operation. As a result, the switching performed within the optical layer will be able to achieve high-speed restoration against failure/degradation of cables, fibers and optical amplifiers.

The OXADM architecture consists of 3 parts; selective port, add/drop operation, and path routing. Selective port permits only the interest wavelength going through and acts as filter. With the switch configuration, add and drop function can be activated in second part of OXADM architecture. The 'accumulation' feature is found in the third part. The functions of OXADM include node termination, drop and add, routing, multiplexing, and also providing mechanism of restoration for point-to-point (P2P), ring, and mesh metropolitan as well as fiber-to-the-home (FTTH) access network. 
The OXADM also provide survivability through restoration against failure by means of dedicated and shared protection that can be applied in wavelength division multiplexing (WDM) ring metropolitan network. In other application, OXADM can also work as any single device such as multiplexer, demultiplexer, OXC, OADM, wavelength selective coupler (WSC), and wavelength roundabout (WRB). With such the excellent features, the OXADM is expected to be unique, universal, and with a high reliability that is used to overcome the various functions in WDM communication network today.

The experimental results showed the value of crosstalk and return loss for OXADM is bigger than $60 \mathrm{~dB}$ and $40 \mathrm{~dB}$ respectively. The results also showed the value of insertion loss was less than $0.06 \mathrm{~dB}$ under ideal condition, the maximum length that can be achieved is 94 $\mathrm{km}$. In the transmission using SMF-28 fiber, with the transmitter power of $0 \mathrm{dBm}$ and sensitivity $-22.8 \mathrm{dBm}$ at a $\mathrm{P} 2 \mathrm{P}$ configuration with safety margin, the required transmission is $71 \mathrm{~km}$ with OXADM. The optical signal-noise-ratio (OSNR) measurements for every function of OXADM are also proposed with the values are bigger than $20 \mathrm{~dB}$.

\section{Wavelength Routed Networks Switching}

Optical networks are high-capacity telecommunications networks based on optical technologies and components that provide routing, grooming, and restoration at the wavelength level as well as wavelength-based services. As networks face increasing bandwidth demand and diminishing fiber availability, network providers are moving towards a crucial milestone in network evolution: the optical network. Optical networks based on the emergence of the optical layer in transport networks, provide higher capacity and reduced costs for new applications such as the Internet, video and multimedia interaction, and advanced digital services (IEC, 2007).

The explosive growth of data, particularly internet traffic, has led to a dramatic increase in demand for transmission bandwidth imposing an immediate requirement for broadband transport networks. Currently telecommunications networks widely employ WDM in single-mode (SM) optical fibers to interconnect discrete network locations and offer high capacity, high-speed and long reach transmission capabilities. The information transmitted in the optical domain is transferred through simple P2P links terminated by Synchronous Digital Hierarchy (SDH) or Synchronous Optical Network (SONET) equipment forming ring and mesh network topologies. This solution requires a number of intermediate service layers introducing complex network architectures. Such a scenario provides unnecessarily high switching granularity, numerous optoelectronic conversions and complicated network management resulting in poor scalability for data services and slow service turn up with high installation, operation and maintenance cost. With the recent technology evolution in the area of optical communications, the WDM transport layer is migrating from simple transmission links into elaborate networks providing similar functionality to that of the SDH/SONET layer, with improved features, higher manageability, lower complexity, and cost-effective. Integrated WDM networks performing switching (Ramaswami, 2001) and routing are deployed in order to overcome the need for multi-layer network architectures (Tzanakaki et al., 2002). In such network scenarios, high capacity optical routes are set in the transport layer forming connections between discrete points of the network topology. In wavelength routed networks switching is performed through OADM and OXC nodes. 


\subsection{Optical Add/Drop Multiplexers (OADM)}

OADM is element that provides capability to add and drop traffic in optical network. The function of an OADM is to insert (add) or extract (drop) one or more selected wavelengths at a designated point in an optical network (Keiser, 2003). An OADM can be passive or active device that located at sites supporting one or two (bi-directional) fiber pairs and enable a number of wavelength channels to be dropped and added reducing the number of unnecessary optoelectronic conversions, without affecting the traffic that is transmitted transparently through the node (Mukherjee, 2006).

The features that an OADM should ideally support are listed below:

- Drop capability of any channel and insertion capability o f a channel on any unused wavelength

- Dynamic reconfiguration supporting fast switching speed (- ms)

- Variable add/drop percentage up to $100 \%$

- Scalable architecture in a modular fashion

- Drop and continue functionality enabling network architectures such as dual homing rings

- $\quad$ Span and ring protection capabilities

- Minimum performance degradation in terms of noise, crosstalk, filtering, etc for add, drop, and through paths

The OADM enhances the WDM terminals by adding several significant features (see Figure 1). The OADM systems have the capacity of up to 40 optical wavelengths. They efficiently drop and add various wavelengths at intermediate sites along the network for solving a significant challenge for existing WDM (IEC, 2007).

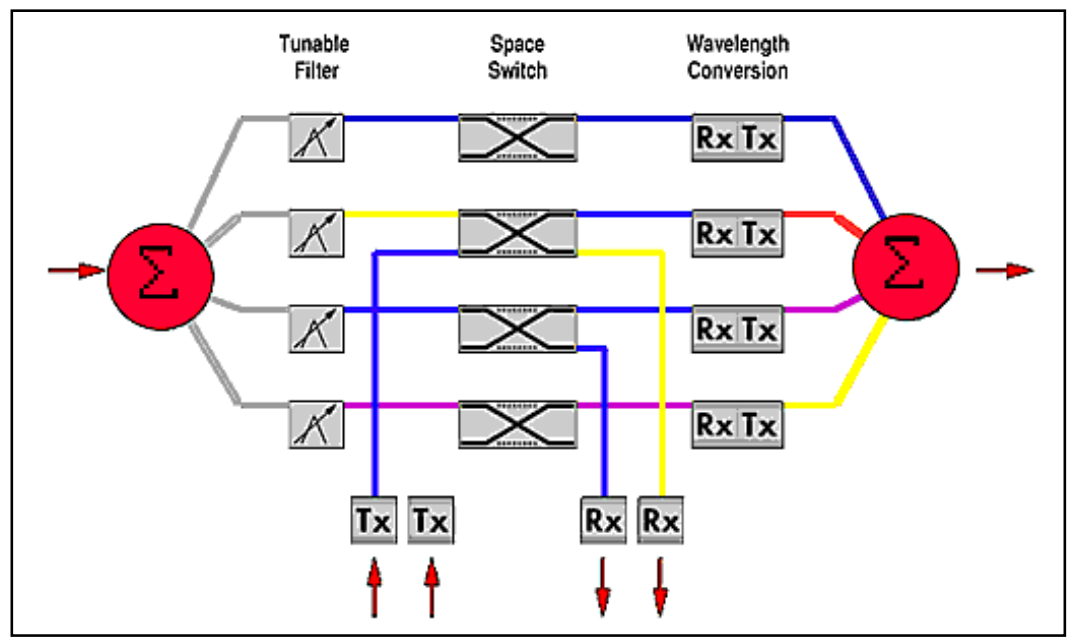

Fig. 1. OADM functionality (IEC, 2007).

Most important, OADM technology introduces asynchronous transponders to allow the optical-network element to interface directly to high revenue generating services. It is now possible for asynchronous transfer mode (ATM), frame relay (FR), native local area networks (LANs), high-bandwidth Internet protocol (IP), and others to connect directly to 
the network via a wavelength in the optical layer. Transponder technology also extends the life of older lightwave systems by accepting its bandwidth directly into the optical layer, converting its frequency to an acceptable standard, and providing protection, and restoration. The OADM also is the foundation of optical bidirectional line switched rings (OBLSRs), which are described in the next module (IEC, 2007).

An OADM can be used in both linear and ring network architectures and in practice operate in either fixed or reconfigurable mode. In fixed OADMs the add/drop and express (through) channels are predetermined and can only be manually rearranged after installation. In reconfigurable OADMs the channels that are added/dropped or pass transparently through the node can be dynamically reconfigured as required by the network. These are more complicated structures but more flexible as they provide provisioning on demand without manual intervention, therefore they can be set up on the fly to allow adding or dropping of a percentage of the overall traffic. The reduction of unnecessary optoelectronic conversions through the use of OADMs introduces significant cost savings in the network (Tzanakaki et al., 2003).

An OADM allows the insertion or extraction of a wavelength from a fiber at a point between terminals. An OADM can operate either statically or dynamically. Some vendors call a dynamic device a reconfigurable OADM (R-OADM). A static version obviously is not as flexible and may require a hardware change if a different wavelength needs to be dropped or added. For example, a static OADM might use two optical circulators in conjunction with a series of fixed-wavelength fiber Bragg gratings (FBG). A dynamic or R-OADM results if the gratings are tunable. Although a dynamic feature adds greater flexibility to a network, this versatility also requires more careful system design. In particular, tunable (wavelengthselectable) optical filters may be needed at the drop receivers, and the OSNR for each wavelength must be analyzed more exactly (Keiser, 2003).

The technology of choice is determined by the functional and the performance requirements of the node. R-OADM can be divided into two categories partly and fully reconfigurable. In partly reconfigurable architectures there is capability to select the channels to be added/dropped, but there is a predetermined connectivity matrix between add/drop and through ports restricting the wavelength assignment function. Fully reconfigurable OADMs also provide the ability to select the channels to be added/dropped, but also offer flexible connectivity between add/drop and through ports, which enables flexible wavelength assignment with the use of tunable transmitters and receivers (Tzanakaki et al., 2003).

R-OADM can be divided into two main generations. The first is mainly applied in linear network configurations and does not support optical path protection while the second is applied in ring configurations and provide optical layer protection to support network survivability. The two most common examples of fully R-OADM: Wavelength selective (WC) and broadcast select (BS) architectures are illustrated in Figure $2 b$ \& 2c. The WS architecture utilizes wavelength (de)multiplexing and a switch fabric interconnecting all express and add/drop ports; while the BS is based on passive splitters/couplers and tunable filters (Mukherjee, 2006).

The tunable filtering, present in the through path, should provide selective blocking of any dropped channels and can be achieved using technologies such as or acousto-optic filters or dynamic channel equalizers (DCEs) based on diffraction grating and liquid crystal or MEMS technologies (Tzanakaki et al., 2003). The overall loss introduced by the through path of the BS solution is noticeably lower than the loss of the WS approach, significantly improving the 
OSNR of the node and therefore its concatenation performance in a practical transmission link or ring network. In addition, the BS design offers superior filter concatenation performance, advanced features such as drop and continue, and good scalability in terms off add/drop percentage (Mukherjee, 2006).

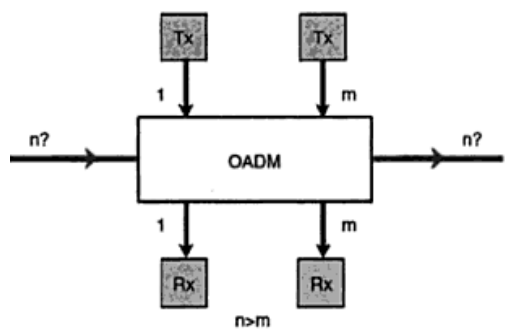

(a)

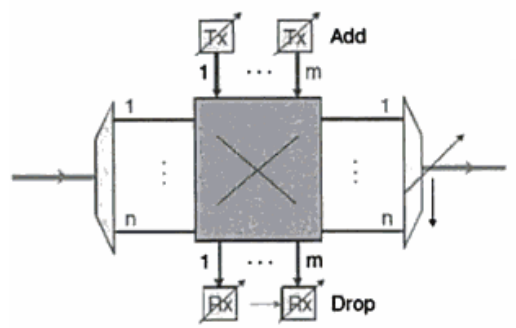

(b)

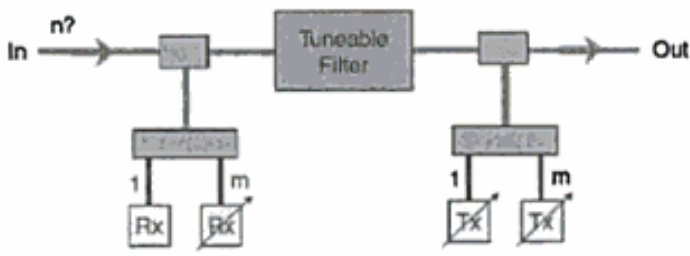

(c)

Fig. 2. (a) Generic OADM architecture, (b) WS OADM architecture, and (c) BS OADM architecture

Figure 3 showed a simple OADM configuration that has four input and four output ports. Here the add and drop functions are controlled by MEMS-based miniature mirrors that are activated selectively to connect the desired fiber paths. When no mirrors are activated, each incoming channel passes through the switch to the output port. Incoming signals can be dropped from the traffic flow by activating the appropriate mirror pair. For example, to have the signal carried on wavelength $\lambda_{3}$ entering port 3 dropped to port 2D; the mirrors are activated as shown in Figure 3. When an optical signal is dropped, another path is established simultaneously, allowing a new signal to be added from port $2 \mathrm{~A}$ to the traffic flow. There are many variations on optical add/drop device configurations depending on the switching technology used. However, in each case the operation is independent of wavelength, data rate, and signal format (Keiser, 2003).

Depending on whether an engineer is designing a metropolitan area network (MAN) or a long-haul network, different performance specifications need to be addressed when implementing an OADM capability in the network. In general, because of the nature of the services provided, changes in the add/drop configuration for a long-haul network tend to occur less frequently than in a MAN. In addition, the channel spacing is much narrower in a long-haul network, and the optical amplifiers which are used must cover a wider spectral band. For an interesting analysis of the Erbium Doped Fiber Amplifier (EDFA) performance 
requirements and the link power budgets used for an OADM capability in a MAN environment (Keiser, 2003).

Wideband long-haul networks are essentially a collection of P2P trunk lines with one or more OADMs for inserting and extracting traffic at intermediate points. Figure 4 depicted a generic long-haul Dense WDM (DWDM) network. Such networks typically are configured as large rings in order to offer reliability and survivability features. For example, if there is cable cut somewhere, the traffic that was supposed to pass through that fault can be routed in the opposite direction on the ring and still reach its intended destination. As shown in Figure 4 are three 10 Gbps DWDM rings and the major switching centers where wavelengths can be regenerated, routed, added, or dropped. The links between DWDM nodes have optical amplifiers every $80 \mathrm{~km}$ to boost the optical signal amplitude and regenerators every $600 \mathrm{~km}$ to overcome degradation in the quality of the optical signals. Extended-reach long-haul networks allow path lengths without regenerators of several thousand kilometers. Also illustrated are typical services between two end-users, such as SONET/SDH, Gigabit Ethernet, or IP traffic (Keiser, 2003).

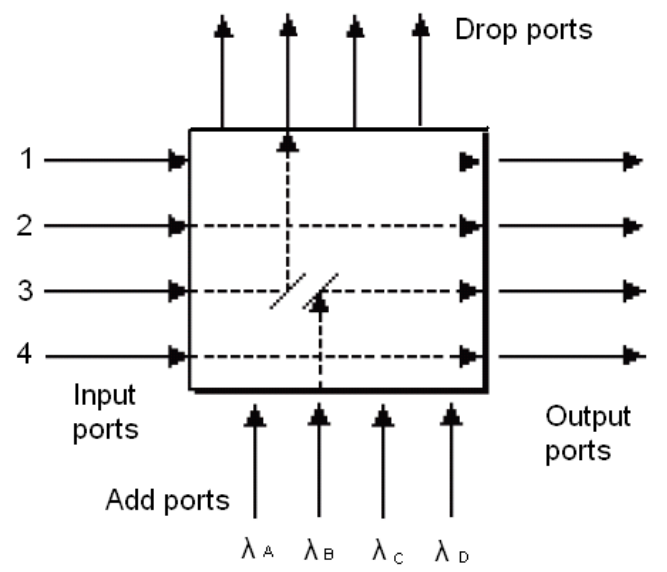

Fig. 3. Example of adding and dropping wavelengths with a $4 \times 4$ OADM device that uses miniature switching mirrors

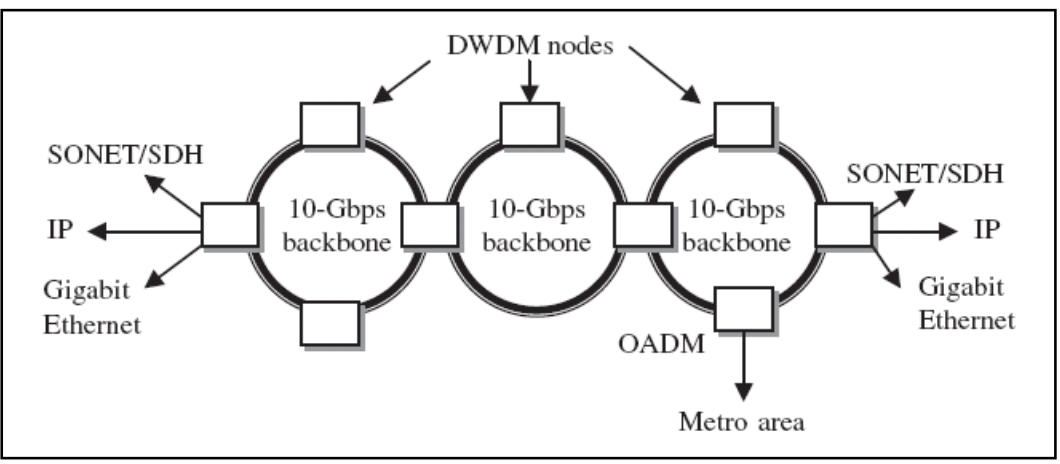

Fig. 4. A generic long-haul DWDM network which is configured as a set of large rings 


\subsection{Optical Cross-Connect (OXC)}

OXC switches optical signals from input ports to output ports. These type of elements are usually considered to be wavelength insensitive, i.e., incapable of demultiplexing different wavelength signals on a given input fiber. OXC is located at nodes cross-connecting a number of fiber pairs and also support add and drop of local traffic providing the interface with the service layer. A basic cross-connect element is the $2 \times 2$ cross point element. A $2 \times 2$ cross point element routes optical signals from two input ports to two output ports and has two states: cross states and bar states (see Figure 5). In the cross state, the signal from the upper input port is routed to the lower output port, and the signal from the lower input port is routed to the upper output port. In the bar state, the signal from the upper input port is routed to the upper output port, and the signal from the lower input port is routed to the lower output port (Mukherjee, 2006).

To support flexible path provisioning and network resilience, OXCs normally utilize a switch fabric to enable routing of any incoming channels to the appropriate output ports and access to the local client traffic. The features that an OXC should ideally support are similar to these of an OADM, but additionally OXCs need to provide:

- Strictly non-blocking connectivity between input and output ports

- Span and ring protection as well as mesh restoration capabilities

Efficient use of fiber facilities at the optical level obviously becomes critical as service providers begin to move wavelengths around the world. Routing and grooming are key areas that must be addressed. This is the function of the OXC, as shown in Figure 6.

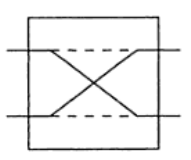

(a) Cross state

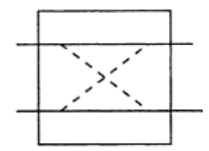

(b) Bar state

Fig. 5. OXC state

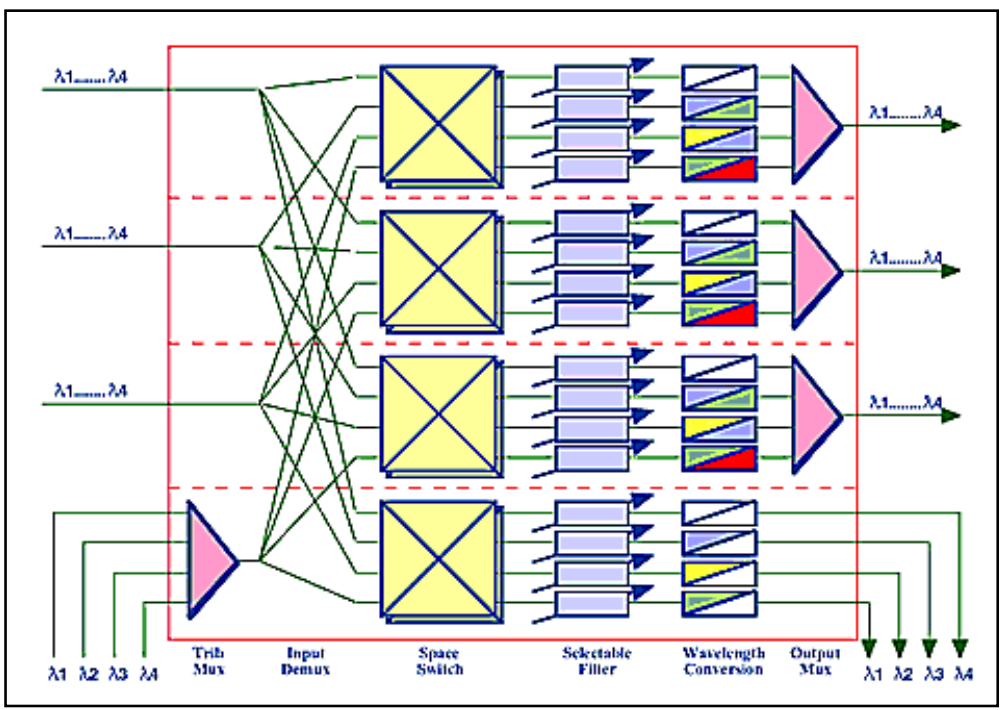

Fig. 6. OXC block diagram (IEC, 2007)

In the optical domain, where 40 optical channels can be transported on a single fiber, a network element is needed that can accept various wavelengths on input ports and route them to appropriate output ports in the network. To accomplish this, the OXC needs three building blocks as illustrated in Figure 7: 
1. Fiber switching - the ability to route all of the wavelengths on an incoming fiber to a different outgoing fiber

2. Wavelength switching - the ability to switch specific wavelengths from an incoming fiber to multiple outgoing fibers

3. Wavelength conversion - the ability to take incoming wavelengths and convert them (on the fly) to another optical frequency on the outgoing port; this is necessary to achieve strictly non-blocking architectures when using wavelength switching (IEC, 2007).

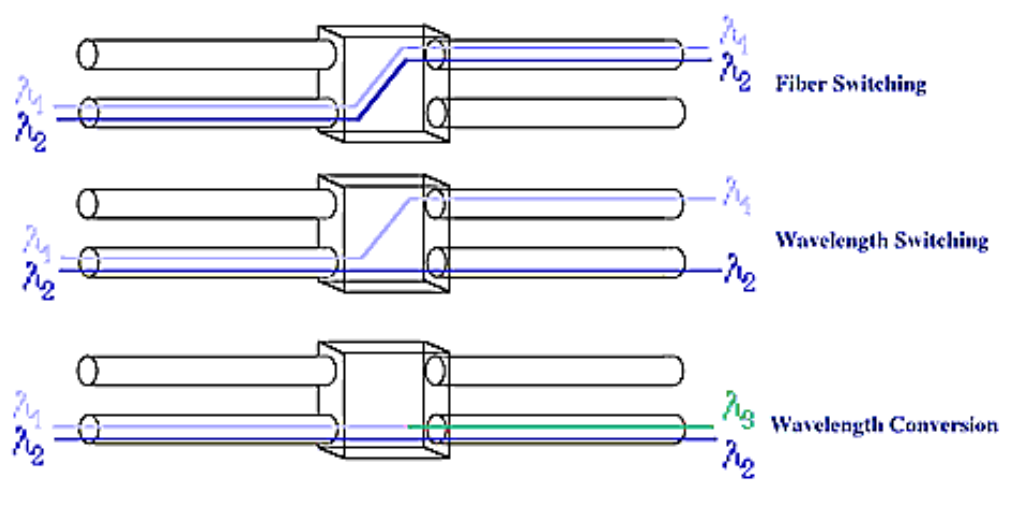

Fig. 7. Switching and conversion with OXC (IEC, 2007).

\section{Optical Cross and Add/Drop Multiplexers (OXADM)}

OXADMs are elements which provide the capabilities of add and drop function and cross connecting traffic in the network, similar to OADM and OXC (Caraglia, 2003; Mutafungwa, 2000; Tsushima, 1998; Tzanakaki, 2003). OXADM consists of three main subsystem; a wavelength selective demultiplexer, a switching subsystem, and a wavelength multiplexer. Each OXADM is expected to handle at least two distinct wavelength channels each with a coarse granularity of $2.5 \mathrm{Gbps}$ of higher (signals with finer granularities are handled by logical switch node such as SDH/SONET digital cross connects or ATM switches. There are eight ports for add and drop functions, which are controlled by four lines of MEMs-optical switch. The other four lines of MEMs switches are used to control the wavelength routing function between two different paths (see Figure 8). The functions of OXADM include node termination, drop and add, routing, multiplexing and also providing mechanism of restoration for $\mathrm{P} 2 \mathrm{P}$, point-to-multipoint (P2MP), ring, and mesh metropolitan. With the setting of the MEMs optical switch configuration, the device can be programmed to function as another optical device such as multiplexer, demultiplexer, coupler, wavelength converter (with fiber grating filter configuration), OADM, WRB, and etc for the single application. 


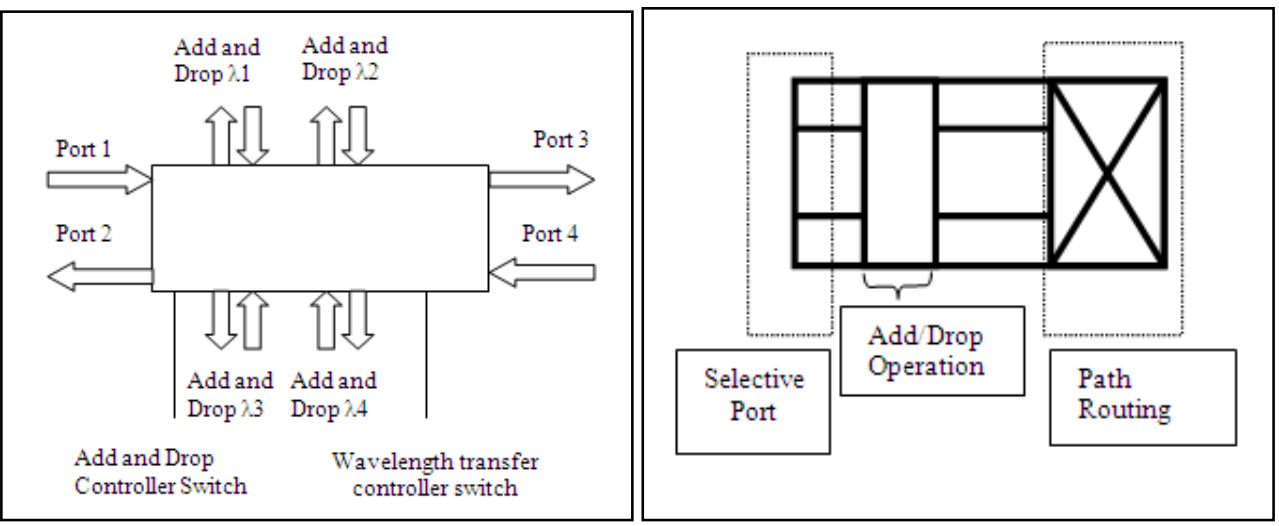

Fig. 8. The block diagram of OXADM architecture Fig. 9. The classification of OXADM

\subsection{OXADM Optical Hybrid Device}

The designed 4-channels OXADM device is expected to have maximum operational loss of $0.06 \mathrm{~dB}$ for each channel when device components are in ideal condition. The maximum insertion loss when considering the component loss at every channel is less than $6 \mathrm{~dB}$. In the transmission using SMF-28 fiber, with the transmitter power of $0 \mathrm{dBm}$ and sensitivity -22.8 $\mathrm{dBm}$ at a point-to-point configuration with safety margin, the required transmission is 71 $\mathrm{km}$ with OXADM without regeneration (Rahman et al., 2006).

The OXADM architecture consists of 3 parts; selective port, add/drop operation, and path routing. Selective port permits only the interest wavelength going through and acts as filter. With the switch configuration, add and drop function can be activated in second part of OXADM architecture. The signals are then re-routing to any port of output. The signals can also be accumulated on one path and exit at any output port. The partition of OXADM architecture is depicted in Figure 9.

\subsection{OXADM Optical Switch}

The control switch for OXADM optical switch is used to change the path of incoming from the input port. When the control switches in 'off' state, no switching occurs and the signal pass through the device as seen from the Figure 10a. But when the control switch B is 'on' state, the signal from the Input 1 will be switch to Output 2 (see Figure 10b). In contrast to the control switch $B$ is in reverse state, the accumulation function occurs which multiplex all the signals from the inputs together and exit at the Output 2. This will be the same if the control switch A is in 'on' state but the output is at Output 1. If both switches are in 'on' state, the signal will be switched to exchange their output port and works as an OXC device. The functional of an OXADM optical switch can be summarized through the truth functional table shown by Table 1 . The incoming signals from the back will be switched to neighbor output port or pass through the device. This is shown in Figure 11. 


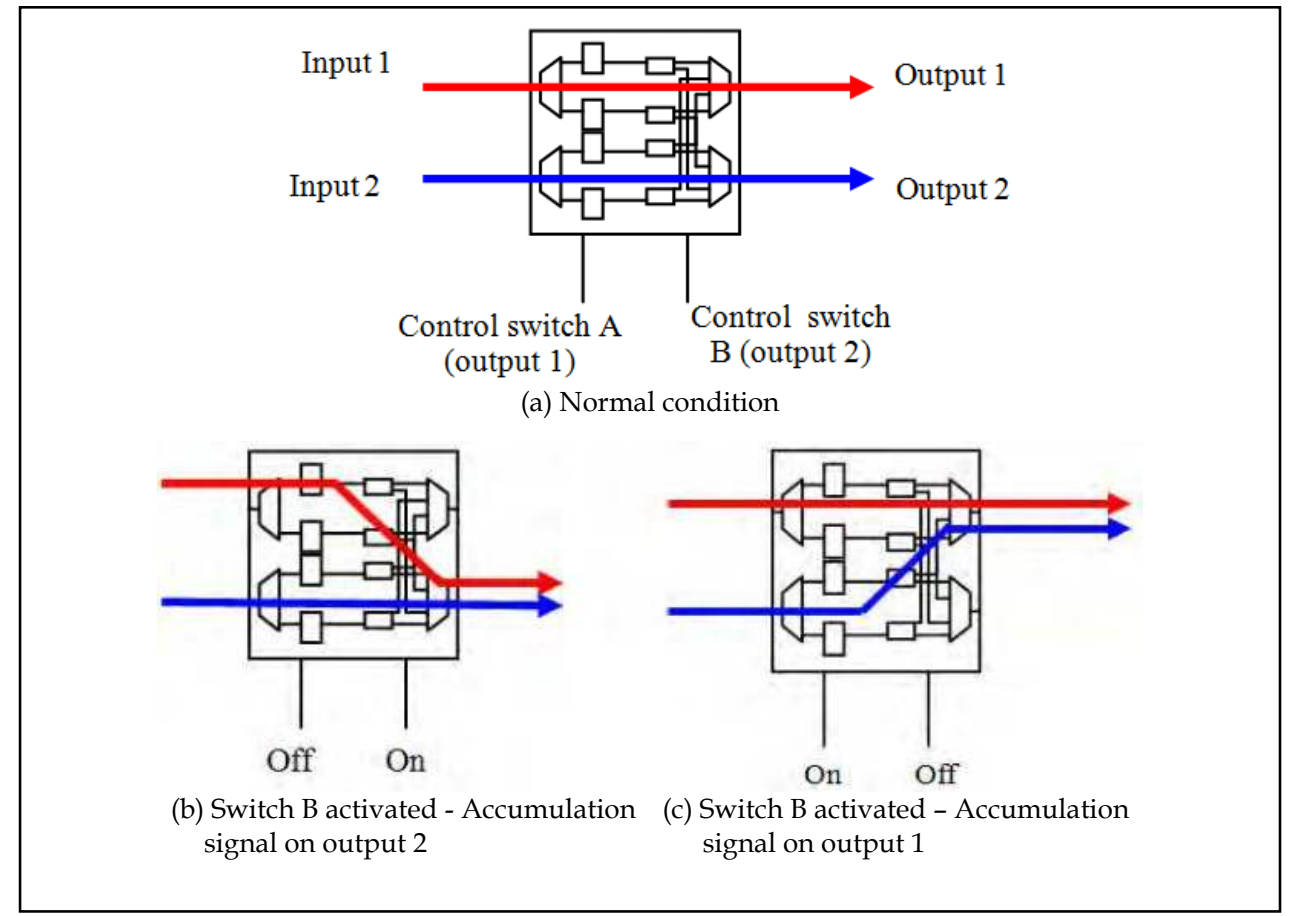

Fig. 10. OXADM optical switch works as re-configurable output port multiplexer

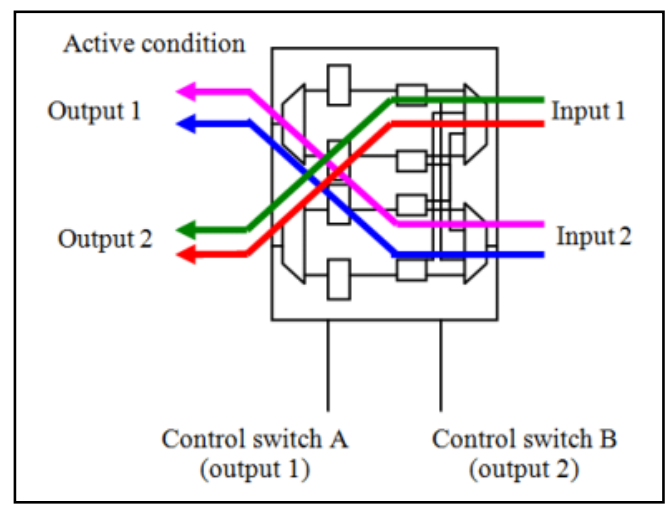

Fig. 11. OXADM optical switch works as $2 \times 2$ demultiplexer. When the switch is activated, the signal will be switched to any output port. 


\begin{tabular}{cccc}
\hline Switch A & Switch B & Output 1 & Output 2 \\
\hline 0 & 0 & $\lambda_{\mathrm{A}}$ & $\lambda_{\mathrm{B}}$ \\
1 & 0 & $\lambda_{\mathrm{A}}+\lambda_{\mathrm{B}}$ & $\mathrm{X}$ \\
0 & 1 & $\mathrm{X}$ & $\lambda_{\mathrm{A}}+\lambda_{\mathrm{B}}$ \\
\hline
\end{tabular}

$\begin{array}{ll}0=\text { Off } & \lambda_{\mathrm{A}}=\text { Signal enters input } 1 \\ 1=\text { On } & \lambda_{\mathrm{B}}=\text { Signal enters input } 2 \\ & \mathrm{X}=\text { No signal }\end{array}$

Table 1. The truth table of OXADM optical switch

\subsection{OXADM Multifunctional Switch}

OXADM can also work as any single device such as multiplexer, demultiplexer, OXC, OADM, WSC, and WRB.

1. Demultiplexer - There are two configuration of demultiplexer using OXADM, with interleaver and without interleaver. The function of interleaver is to separate the incoming signal before entering the OXADM ports (Figure 12ai). In contrast, the signal will enter the back port and has automatically routed to their respective path (Figure 12aii).

2. Multiplexer - The input signals enter the add ports of OXADM and the multiplexed signal out of the signal via output port (Figure 12b).

3. OADM - The separated wavelengths out of the interleaver have a capability to add/drop function before they are combined and exit one of the output ports of OXADM (Figure 12c).

4. WSC - Two WSC devices will be produced by OXADM. The signal will enter the input port and will be separated out through the drop port of OXADM (Figure 12d).

5. OXC - The concept is similar to OADM but the OXADM also offer the function of crossconnect the signals. The function is almost the same with OXC device (Figure 12e).

6. WRB - The new invented device that offer the management function of wavelengths. Different with circulator in which the inputs and outputs are built separately (Figure 12f).

\subsection{Other Application}

FTTH is a simple, inexpensive, ideal, and attractive many parties in optical communication today. A number of factors are increasing the interest among network service providers in offering the triple play services of high-speed data access, voice, and video. Most importantly, subscribers are finding a growing number of applications that drive their desire for higher bandwidth, including Internet access, interactive games, and video delivery. Since the fiber offers a vast amount of bandwidth that can be utilized for communication, one of utilizing this is signal multiplexing. Due to the large bandwidth and the associated high bit rates, the multiplexing process is beyond the capabilities of pure electronic methods and has to be implemented optically as well. As the reach of fiber is being extended to the access network it is economically attractive to share fibers between 
different end-users without adding active components in the network (Menif and Fathallah, 2007).

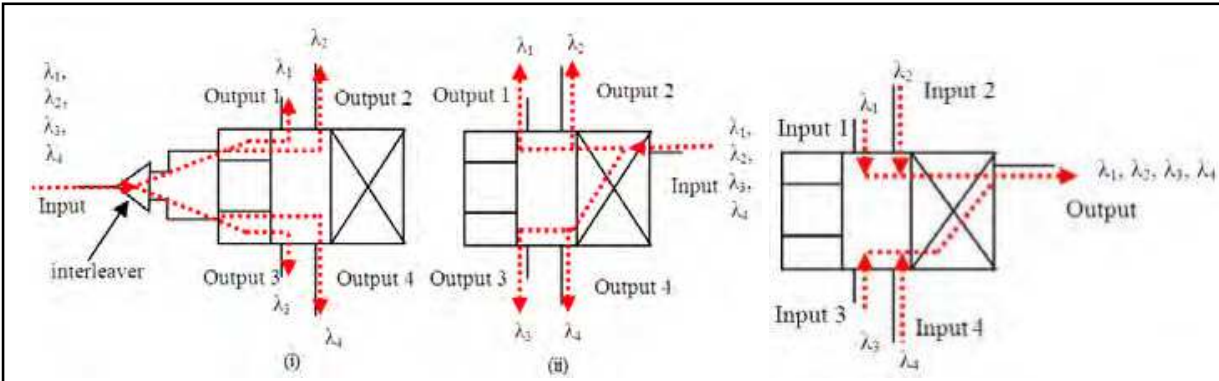

(a) The functional diagram of OXADM:DEMUX

1x4, (i) Configuration 1 (ii) Configuration 2

(b) The functional diagram of OXADM:MUX

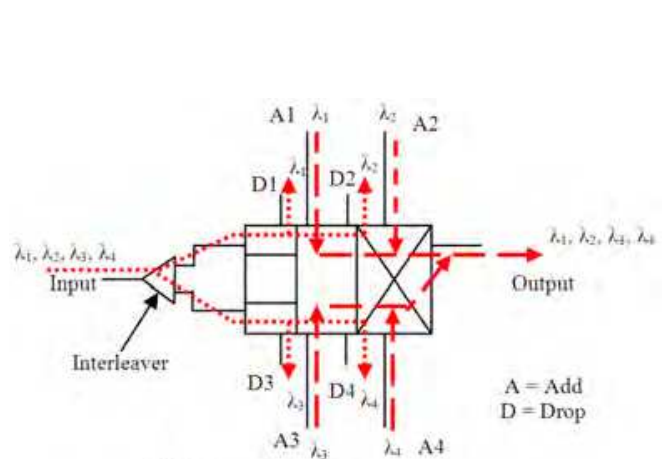

(c) The functional diagram of OXADM:OADM $1 \times 4$

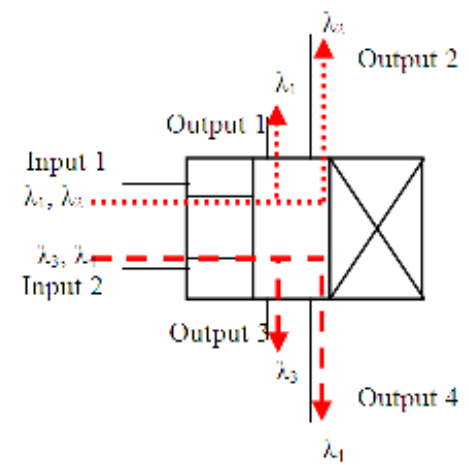

(d) The block diagram of OXADM:WSC
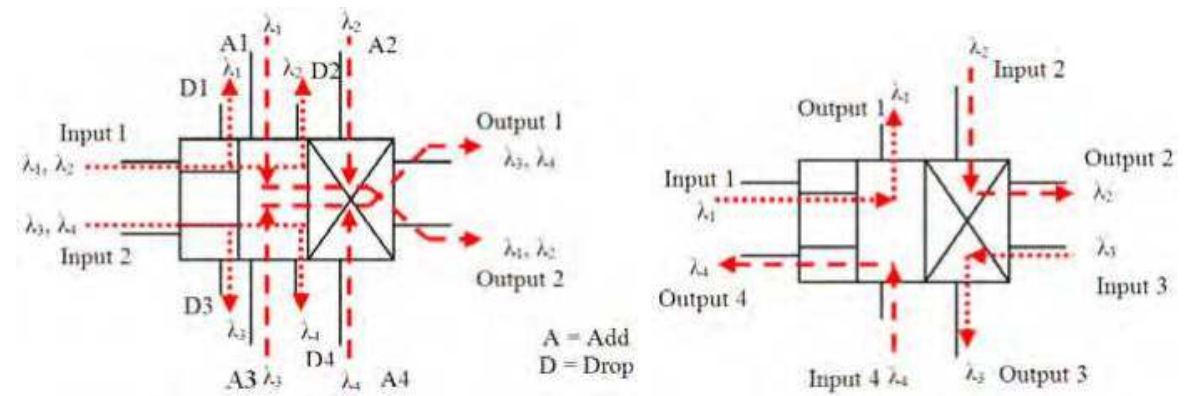

(e) The functional diagram of OXADM:OXC

(f) The functional diagram of OXADM:WRB

Fig. 12. OXADM multifunctional switch

It involves the full installment of fiber from central office (CO) till to customer houses which is called premises. Recently, installation of FTTH technology has started to accelerate as a strong alternative to the existing broadband access technologies based on copper pairs (Digital Subscriber Line, DSL) and coax (cable modems). This worldwide acceleration is largely due to both the considerable decrease in capital expenses (CAPEX) of introducing 
FTTH connectivity and its "future proof" nature in providing ever increasing user bandwidth requirements (Yuksel et al., 2008). This technology ensures low operational expenditures (OPEX) due to all elements in used are the passive optical device with small number used. The maximum distance achievable is $20 \mathrm{~km}$ with gigabit of transmission rate. FTTH consists of 3 significant elements: optical line terminal (OLT), optical splitter, and optical network unit (ONU). The designed OXADM is can also used as the wavelength management in OLT architecture for excellently FTTH. It has 4 inputs terminal which represent the 4 different signal carriers to be multiplexed and exit at Output 1 . Three wavelengths are used typically $1310 \mathrm{~nm}$ for data/voice upstream transmission and $1490 \mathrm{~nm}$ for the downstream data/voice transmission. Meanwhile $1550 \mathrm{~nm}$ is used to transmit downstream video signal.

Since the possible wavelength for communication is $1200-1600 \mathrm{~nm}, 1625-1650 \mathrm{~nm}$ wavelength regions is commonly considered for in-service monitoring purpose without affecting the services to other end-users. Additional wavelength $1625 \mathrm{~nm}$ will be adding up to the system to carries the troubleshooting signal for line status monitoring purposes. In the downstream direction (OLT to users), packets are broadcast by the OLT and extracted by their destination ONUs based on their media access control (MAC) address. In the upstream direction (users to OLT), each ONU will use a time shared channel (TDM) arbitrated by the OLT. OLT is function to aggregates Ethernet traffic from remote ONU devices through passive optical splitters. The signals then are sent to the customer premises. This can be defined in Figure 13 with the wavelength allocation highlighted.

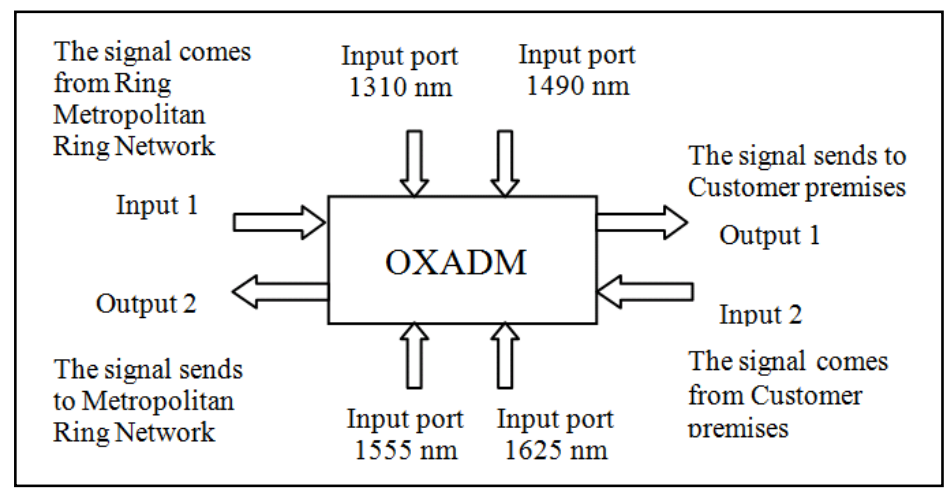

Fig. 13. OXADM function as the wavelength management element in OLT in FTTH

\subsection{Device Comparison}

The OXADM device will be compared with two existing switching devices; directional coupler (DC) switch and OXC. The non-selective DC switch has two states and one control element. It has fixed number of input and output port that is two. The wide bandwidth signal comes from the input port with switch to either one of output ports. It works bidirectional with symmetrical function (Palais, 2005). Figure 14 showed the mechanism of switching for directional coupler switch in normal (a) and active condition (b) \& (c). The application of DC switch is to control the signal path in WDM network and optical storage; and can also perform the function of OADM in optical distributed network 
OXC is the directional coupler witch but with many ports. The functional of OXC is crossconnecting between output and input port (see Figure 15) (Mutafungwa, 2001). Same with OXADM, the OXC is selective device but it does not have 'accumulation' feature. In contrast with OXADM, OXC works bi-directional with symmetrical function. The application of $\mathrm{OXC}$ is as a switching device in mesh network configuration and also in optical storage. Table 2 summarized the differences of OXADM as compared with DC and OXC.

\begin{tabular}{cccc}
\hline Features & OXADM & DC & OXC \\
\hline Selective & Yes & No & Yes \\
Accumulation & Yes & No & No \\
Scalability & Yes & No & Yes \\
$\begin{array}{c}\text { Symmetrical } \\
\text { function }\end{array}$ & No & Yes & Yes \\
\hline
\end{tabular}

Table 2. Comparison between OXADM, DC, and OXC

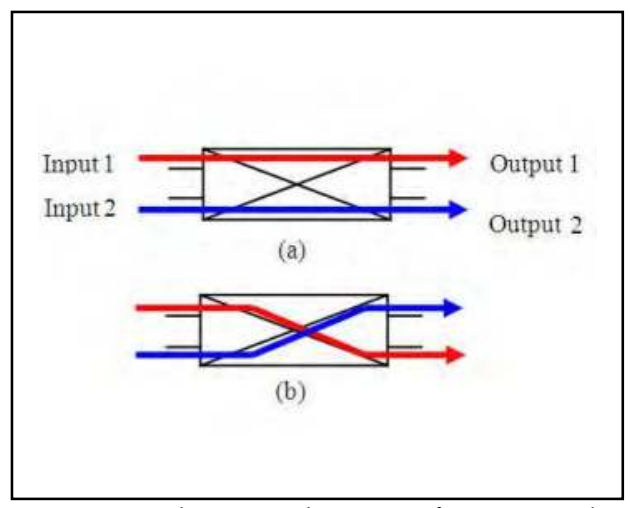

Fig. 14. Switching mechanism of DC optical switch, a) normal (b) activate

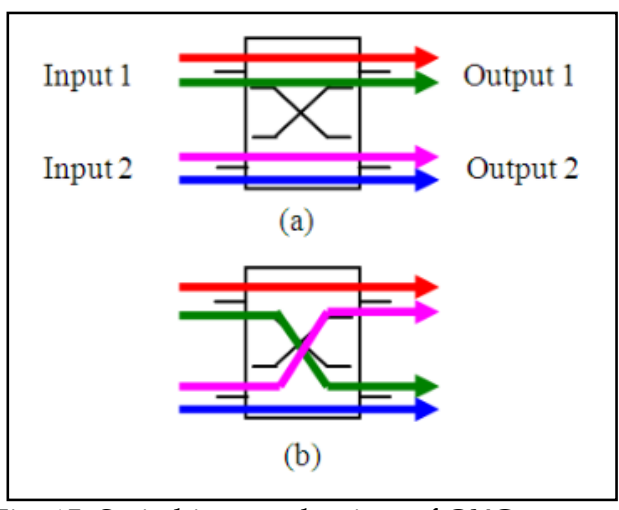

Fig. 15. Switching mechanism of OXC, a) normal (b) activate

\section{Experimental Results and Discussions}

\subsection{Experimental Setup}

Two parameters have been studied experimentally to ensure the interference of uninterested signal is minimized. Figure 16 presented the experimental set up to measure the crosstalk at two ports of OXADM and the results have been redrawn in Figure 17 and 18 respectively. The crosstalk value is bigger than $60 \mathrm{~dB}$ means the interested wavelength is in safety level and the transmitted data can be interpreted at any receiver end. 


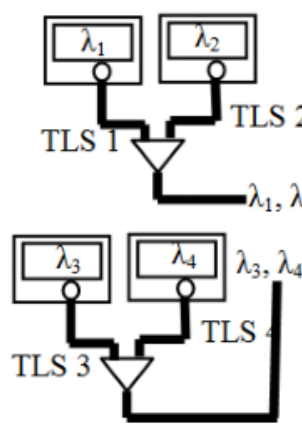

Demultiplexer

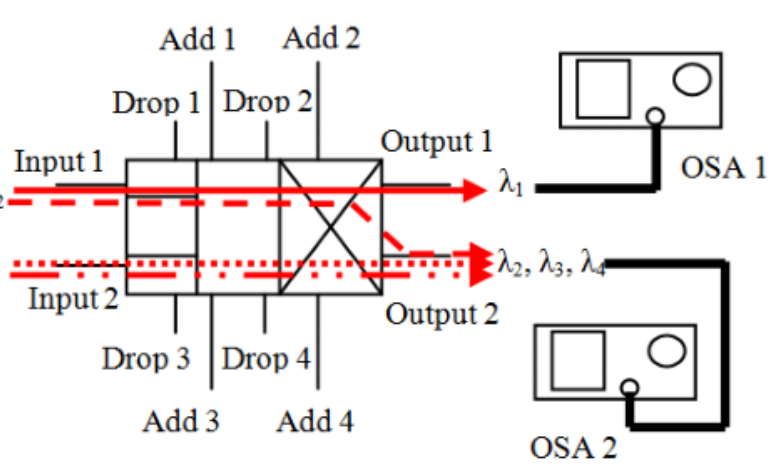

(a) Configuration 1

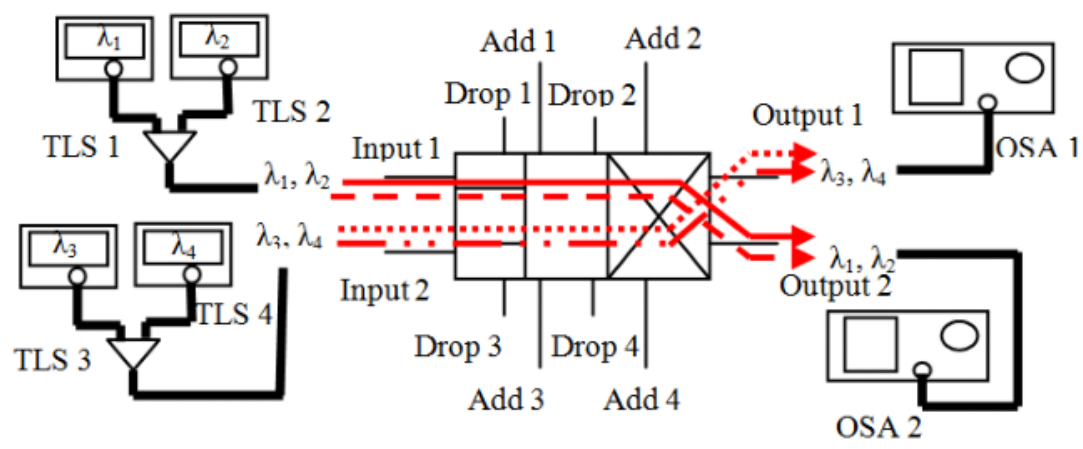

(b) Configuration 2

Fig. 16. Crosstalk measurement set up

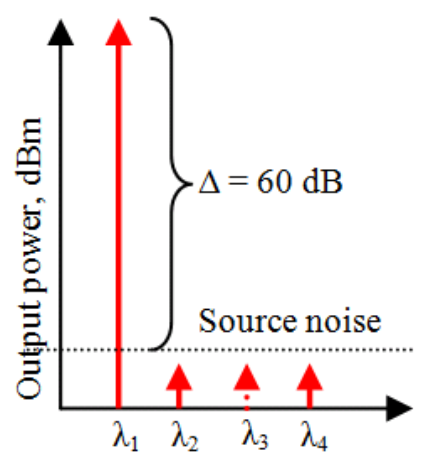

Wavelength, nm

(a) Output 1

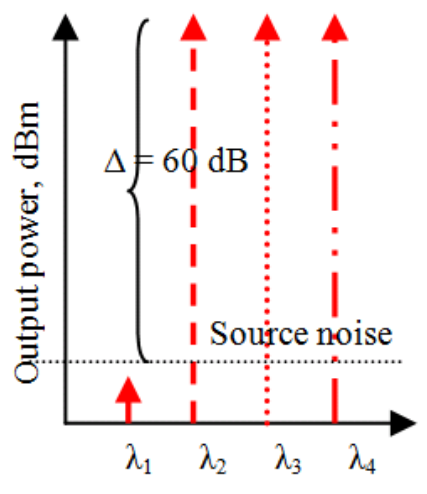

Wavelength, $\mathrm{nm}$

(b) Output 2

Fig. 17. Redrawing of measured output port at every port for configuration 1 


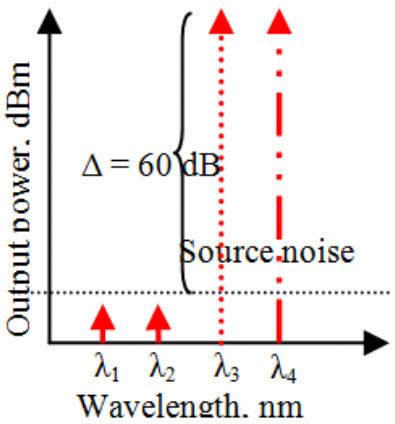

(a) Output 1

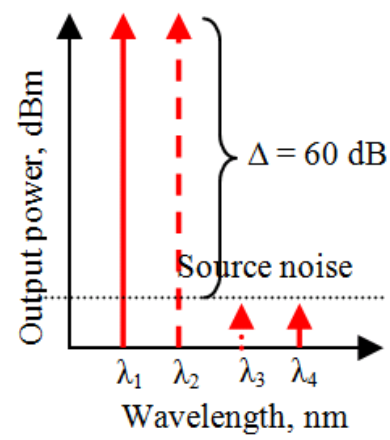

(b) Output 2

Fig. 18. Redrawing of measured output port at every port for configuration 2

The other parameter should be considered for bi-directional device is return loss. Return loss is the disturbance of uninterested signal against the direction of interested signal. This can be explained using Figure 19. The return loss is measured by using set up in Figure 20 and the result is shown in Figure 21. The return signal coming out from the input port is routing to OSA 3 using optical circulator. The value is $40 \mathrm{~dB}$ which is higher than minimum safety value. Both experimental have shown that the OXADM optical switch has a good and acceptable value of crosstalk and return loss.

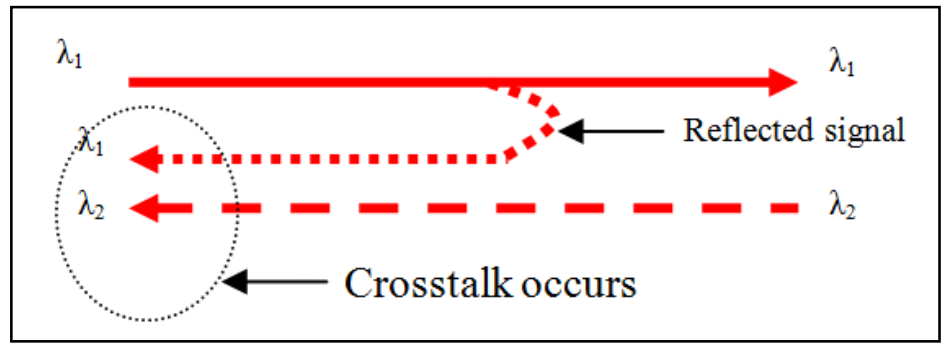

Fig. 19. Return loss or leak reflected signal which contributes to crosstalk phenomena in bidirectional device.

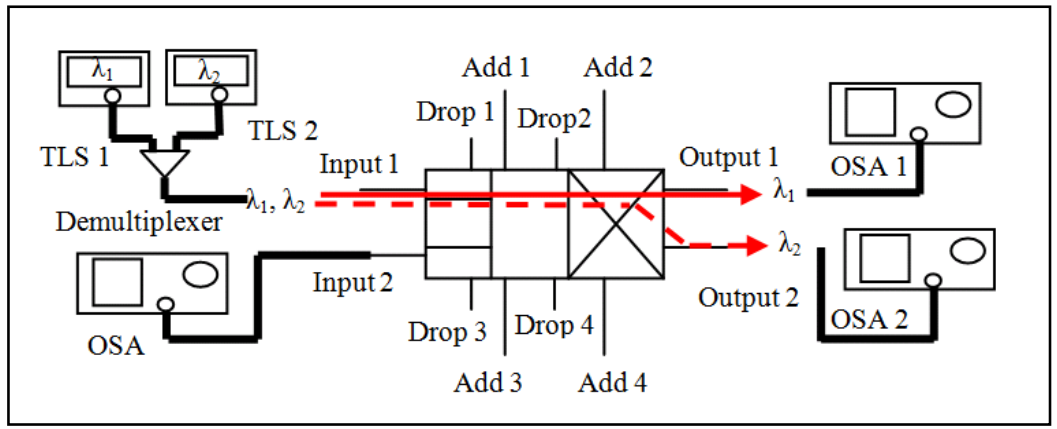

Fig. 20. Return loss measurement set up 


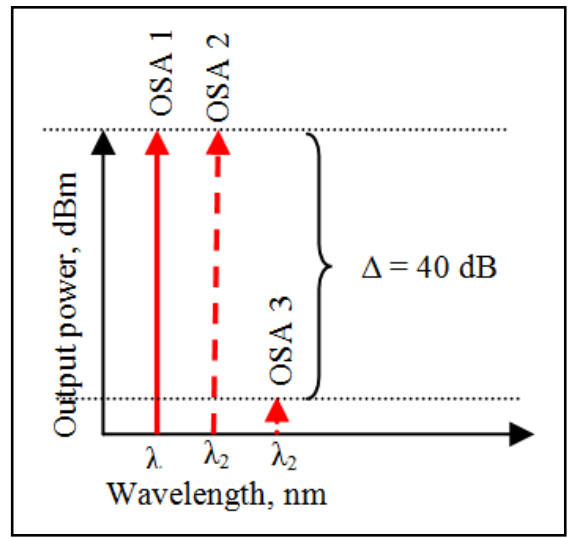

Fig. 21. Redrawing of measured output port at every port for configuration 2 for return loss measurement

\subsection{Experimental Results}

The OXADM device is characterized by using two tunable light sources and two optical spectrum analyzers. The designed 4-channel OXADM device is expected to have maximum operational loss of $0.6 \mathrm{~dB}$ for each channel when device components are in ideal condition. The maximum insertion loss when considering the component loss at every channel is $6 \mathrm{~dB}$. The testing is carried out for every single function of OXADM. The function includes bypass, path exchange and accumulation. The single operating wavelength test (wavelength is $1510 \mathrm{~nm}$ ), the results show the OSNR value for bypass function is $20 \mathrm{~dB}$ and path exchange is also $20 \mathrm{~dB}$. Each measurement result is indicated in Figure 22 till 24.

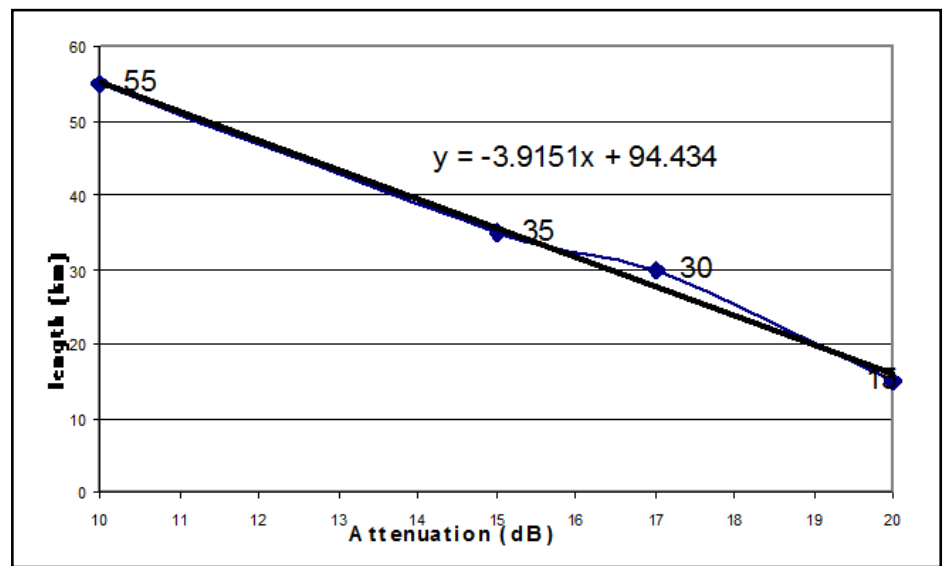

Fig. 22. The decrement of kilometers occurs by increasing the attenuation of OXADM which represent the device losses 


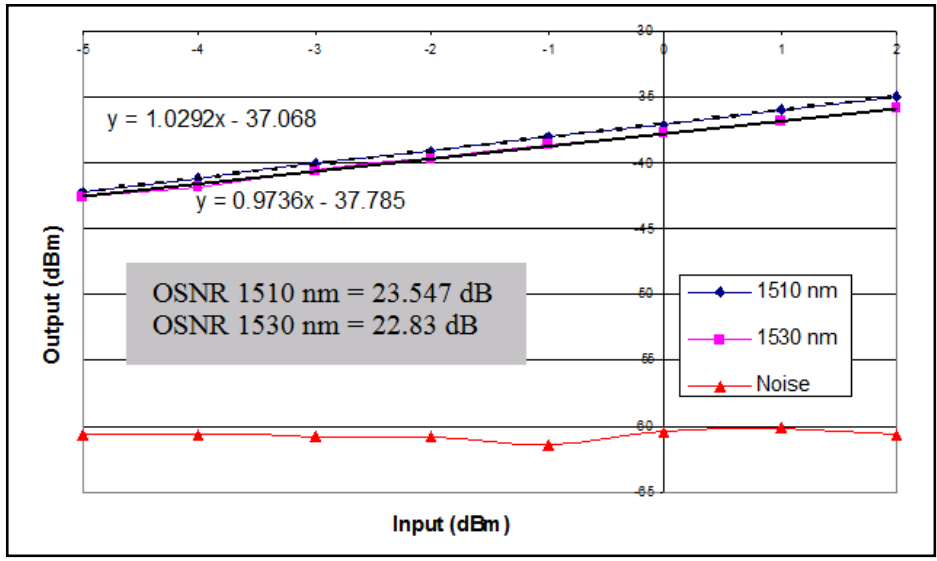

Fig. 23. The measured output power at two operating wavelength for bypass operation

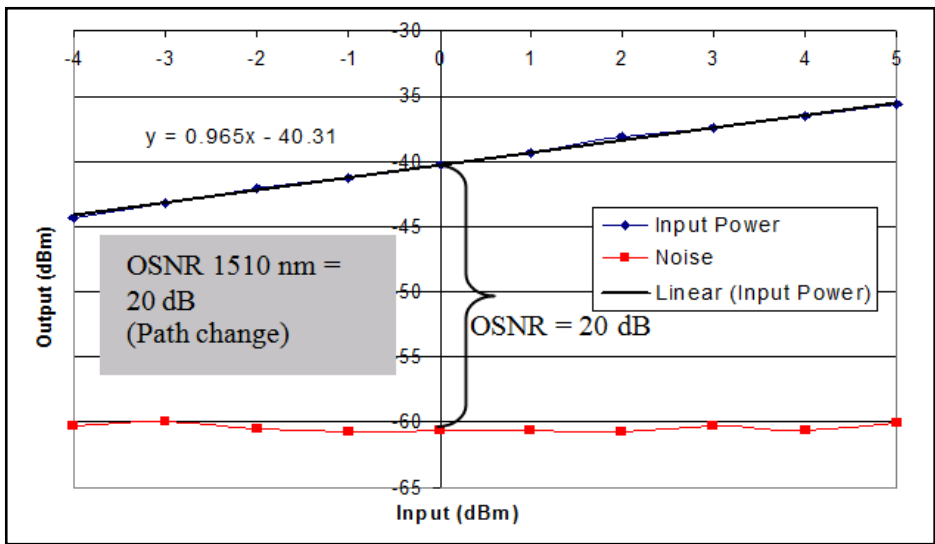

Fig. 24. The measured output power for path exchange operation

The path splitting function (accumulation function in reverse mode as Figure $10 \mathrm{~b}$ and 10c) is also applied and the result shown in Figure 25 with OSNR $>24 \mathrm{~dB}$. For backward operation as depicted in Figure 26, the OSNR values for cross-connecting function (as Figure 11) are bigger than $22 \mathrm{~dB}$. This can be defined that the level of signal is $20 \mathrm{~dB}$ higher than noise level for all single functions of OXADM optical switch. The $20 \mathrm{~dB}$ reference indicates the acceptable value for the signal to noise ratio in data communication. 


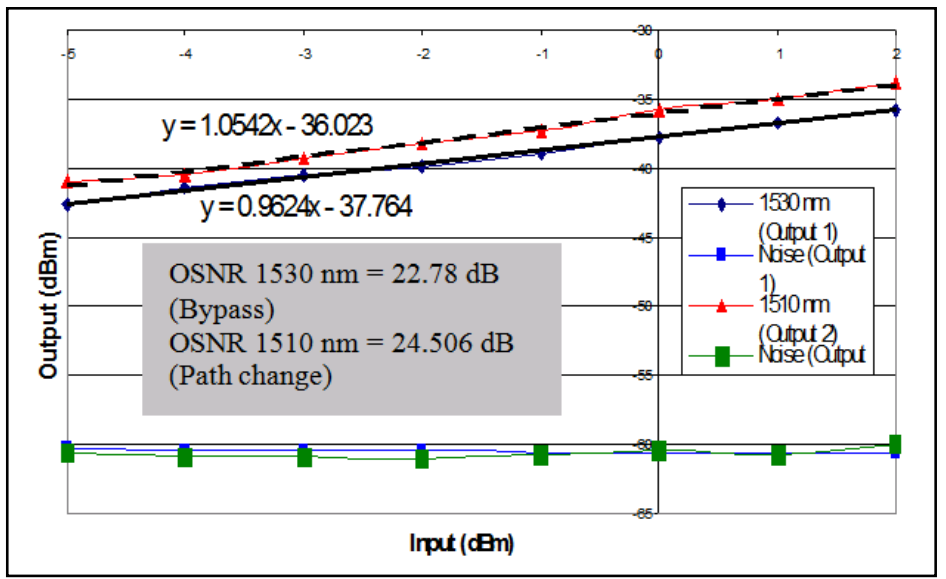

Fig. 25. The measured output power two operating wavelength for path splitting operation (accumulation function in reverse mode)

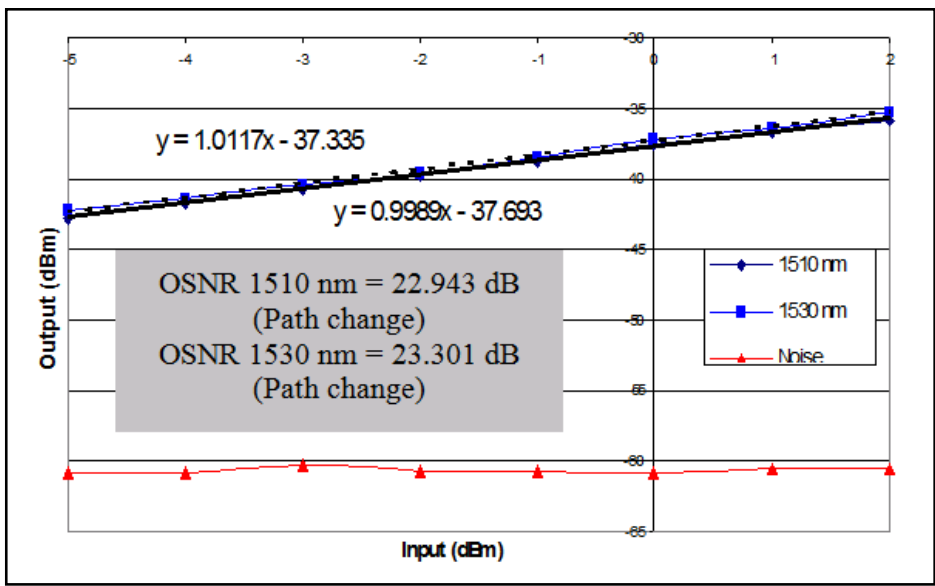

Fig. 26. The measured output power at two operating wavelengths for path exchange operation

\section{The Developed Prototype}

A prototype was designed and developed to enable us to evaluate the performance in an actual propagation environment as illustrated in Figure 27 and 28. 


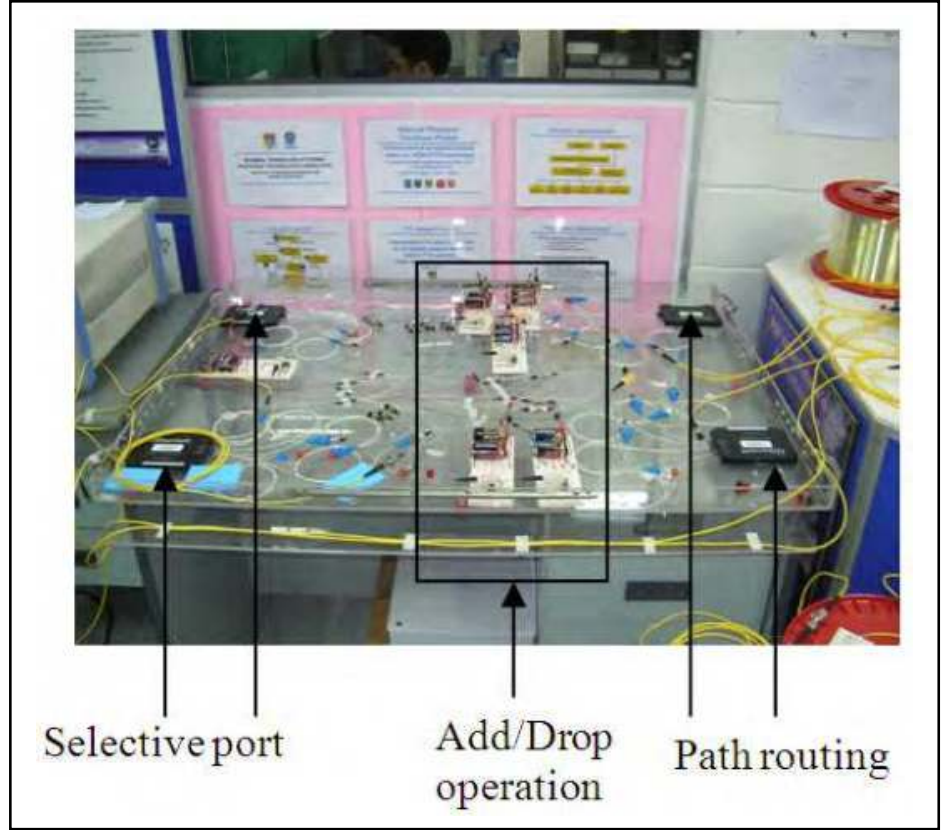

Fig. 27. Photographic view of OXADM device set up

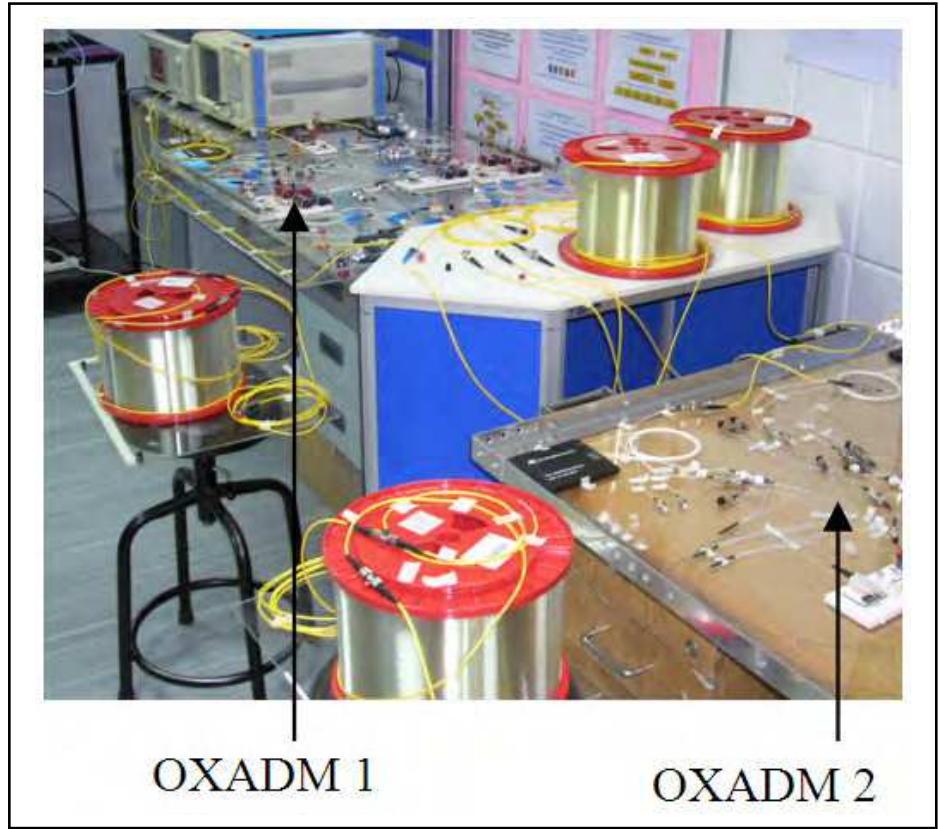

Fig. 28. Photographic view of two OXADM device prototypes set up in P2P network 


\section{Conclusion}

A new switching device which utilizes the combined concepts of OADM and OXC operation is presented through the development of OXADM. The experimental results show the value of crosstalk and return loss is bigger than $60 \mathrm{~dB}$ and $40 \mathrm{~dB}$ respectively. In our previous results have also shown the value of insertion loss was less than $0.06 \mathrm{~dB}$ under ideal condition, the maximum length that can be achieved is $94 \mathrm{~km}$. While when considering the loss, with the transmitter power of $0 \mathrm{dBm}$ and sensitivity $-22.8 \mathrm{dBm}$ at a P2P configuration with safety margin, the required transmission is $71 \mathrm{~km}$ with OXADM. The OXADM switching mechanism has been explained and compare with other existing optical switch; DC optical switch and OXC. The OXADM optical device is particularly designed for WDM metro application. It can be used as restoration switch in FTTH network. OXADM can also work as any single device such as demultiplexer, multiplexer, OADM, OXC, WSC, and WRB. In other application, the OXADM can also provide survivability through restoration against failure by means of dedicated and shared protection that can be applied in WDM ring metropolitan network.

\section{Acknowledgement}

This project is supported by Ministry of Science, Technology and Innovation (MOSTI), Government of Malaysia, through the National Top-Down Project fund and National Science Fund (NSF). The authors would like to thank the Photonic Technology Laboratory in Institute of Micro Engineering and Nanoelectronics (IMEN), Universiti Kebangsaan Malaysia (UKM), Malaysia, for providing the facilities to conduct the experiments. The OXADM had firstly been exhibited in 19th International Invention, Innovation and Technology Exhibition (ITEX 2008), Malaysia, and was awarded with Bronze medal in telecommunication category.

\section{References}

Caraglia, C.; Haffaouz, S.; Zantvoort, J.V.; Leijtens, X. \& Smit, M. (2003). A Photonic Integrated Add-Drop Multiplexing for a 1.6 Tbits/s Optical Ring Network, Proceeding Symposium IEEE/LEOS Benelux Chapter, Enshede, pp. 69-72, 2003

International Engineering Consortium. (2007). Optical Networks, White Paper, 2007, Available: http://www.iec.org/online/tutorials/opt_net/index.asp

Keiser, G. (2003). Optical Communications Essentials, McGraw Hill, New York, US, ISBN: 0-07143353-8

Menif, M. \& Fathallah, H. (2007). An Encoder/decoder Device Including a Single Reflective Element for Optical Code Division Multiple Access System. Journal of Optical Communications, Vol. 28, No. 3 (2007) 172-174, ISSN: 0173-4911

Mukherjee, B. (2006). Optical WDM Networks (Optical Networks), Springer, ISBN: 978-0-38729055-3

Mutafungwa, E. (2001). An Improved Wavelength-selective All Fiber Cross-connect Node, Proceedings of 2001 IEEE Workshop on High Performance Switching and Routing, pp. 9396, ISBN: 0-7803-6711-1, Dallas, TX, USA, 2001 
Tsushima, H.; Hanatani, S.; Kanetake, T.; Fee, J.A. \& Liu, S.A. (1998). Optical Cross-connect System for Survivable Optical Layer Networks, Hitachi Review, Vol. 47, No. 2, (1998) 85-90, ISSN: 0018-277X

Palais, J.C. (2005). Fiber Optic Communication, Prentice Hall, New Jersey, ISBN: 9780130085108

Rahman, M.S.A.; Husin, H.; Ehsan, A.A. \& Shaari, S. (2006). Analytical Modeling of Optical Cross Add and Drop Multiplexing Switch, Proceedings of 2006 IEEE International Conference on Semiconductor Electronics, pp. 290-293, ISSN: 0-7803-9731-2, Kuala Lumpur, Malaysia, 2006

Ramaswami, R. (2001). All-Optical Crossconnects in the Transport Network, Proceedings of 2001 Optical Fiber Communication Conference and Exhibit (OFC 2001), Vol. 3, pp. WZ1WZ1, ISBN: 1-55752-655-9, Anaheim, CA, USA, March 2001

Tzanakaki, A.; Wright, I. \& Sian, S.S. (2002). Wavelength Routed Networks: Benefits and Design Limitations, Proceedings of Cybernetics and Informatics (SCI2002), Orlando, Florida, July 2002

Tzanakaki, A.; Zacharopoulus, I. \& Tomkos, I. (2003). Optical Add/drop Multiplexers and Optical Cross-connects for Wavelength Routed Network, Proceedings of 5th International Conference on Transparent Optical Networks (ICTON 2003), pp. 41-46, ISBN: 0-7803-7816-4, Warsaw, Poland, June 2003

Yuksel, K.; Moeyaert, V.; Wuilpart, M. \& Mégret, P. 2008. Optical layer monitoring in passive optical networks (PONs): a review. Proceedings of $10^{\text {th }}$ Anniversary International Conference on Transparent Optical Networks (ICTON 2008), pp. 92-98, ISSN: 978-1-4244-2626-3, Athens, Greece, June 2008 


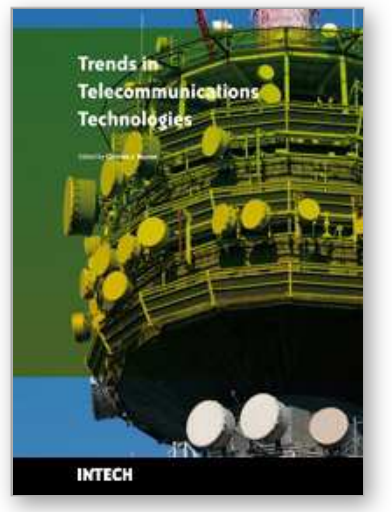

\author{
Trends in Telecommunications Technologies \\ Edited by Christos J Bouras
}

ISBN 978-953-307-072-8

Hard cover, 768 pages

Publisher InTech

Published online 01, March, 2010

Published in print edition March, 2010

The main focus of the book is the advances in telecommunications modeling, policy, and technology. In particular, several chapters of the book deal with low-level network layers and present issues in optical communication technology and optical networks, including the deployment of optical hardware devices and the design of optical network architecture. Wireless networking is also covered, with a focus on WiFi and WiMAX technologies. The book also contains chapters that deal with transport issues, and namely protocols and policies for efficient and guaranteed transmission characteristics while transferring demanding data applications such as video. Finally, the book includes chapters that focus on the delivery of applications through common telecommunication channels such as the earth atmosphere. This book is useful for researchers working in the telecommunications field, in order to read a compact gathering of some of the latest efforts in related areas. It is also useful for educators that wish to get an up-to-date glimpse of telecommunications research and present it in an easily understandable and concise way. It is finally suitable for the engineers and other interested people that would benefit from an overview of ideas, experiments, algorithms and techniques that are presented throughout the book.

\title{
How to reference
}

In order to correctly reference this scholarly work, feel free to copy and paste the following:

Mohammad Syuhaimi Ab-Rahman and Boonchuan Ng (2010). The Asymmetrical Architecture of New Optical Switch Device, Trends in Telecommunications Technologies, Christos J Bouras (Ed.), ISBN: 978-953-307-0728, InTech, Available from: http://www.intechopen.com/books/trends-in-telecommunications-technologies/theasymmetrical-architecture-of-new-optical-switch-device

\section{INTECH}

open science | open minds

\section{InTech Europe}

University Campus STeP Ri

Slavka Krautzeka 83/A

51000 Rijeka, Croatia

Phone: +385 (51) 770447

Fax: +385 (51) 686166

www.intechopen.com

\section{InTech China}

Unit 405, Office Block, Hotel Equatorial Shanghai

No.65, Yan An Road (West), Shanghai, 200040, China 中国上海市延安西路65号上海国际贵都大饭店办公楼 405 单元

Phone: +86-21-62489820

Fax: $+86-21-62489821$ 
(C) 2010 The Author(s). Licensee IntechOpen. This chapter is distributed under the terms of the Creative Commons Attribution-NonCommercialShareAlike-3.0 License, which permits use, distribution and reproduction for non-commercial purposes, provided the original is properly cited and derivative works building on this content are distributed under the same license. 